\title{
Ways for the Control of the Total Toxicity of Environmental Objects and their Instrumental Providing
}

\author{
Starodub NF*, Guidotti M²*, Shavanova KE'1, Taran MV1 and Son'ko RV1 \\ ${ }^{1}$ National University of Life and Environmental Sciences of Ukraine, Heroyiv Oborony st., 15, Kyiv-03041, Ukraine \\ ${ }^{2}$ Institute of Molecular Sciences and Technology (ISTM), National Research Council (CNR), via G. Venezian 21, I-20144, Milano, Italy
}

\begin{abstract}
As it's known a lot of chemical substances of a different types are released to the environment and they form a big dangerous for living organisms. To prevent such threats there is necessary to provide continuously monitor not only the level of overall toxicity of the environment, but also to control the degree of stress on the genetic apparatus of living organisms, determining genotoxicity of various unfavorable factors, including various anthropological effects. The total toxicity may be determined with the participation of living organisms. In this review some most applicable methods with the using number of sensitive objects such as Daphnia sp., bioluminescent bacteria and plants are considered at the control of the total toxicity of environmental factors. It is described the main principles of the realization of these methods, peculiarities of their application and instrumental providing.
\end{abstract}

Keywords: Total toxicity; Control; Bioluminescent bacteria; Daphnia sp.; Yeasts; Plants; Instrumental approaches

\section{Introduction}

A different individual chemical substances (ChS) and their mixtures are wide dispersed in environment and such situation leads to a great danger for living organisms. To counteract this undesirable situation it arises a urgent necessity in the organizing permanent control since, as a rule, the $\mathrm{ChS}$ are toxic, stable, and have the ability for bioaccumulation and long term transferring in atmosphere [1]. These substances may influence on the living organisms far from places of their production and on remote territories. So, it was discovered chemicals in Arctic where they are never been produced and where their concentration were increased up to level which is threatening for wild nature and humanities. And it is confirming the global character of their dispersion $[2,3]$. According to classification from the position of ecology and sources of manufacturing $\mathrm{ChS}$ may be divided on: pesticides, products of industry (polychlorinated biphenyl's, hexachlorbensens) and concomitant substances (dioxins, furans and polycyclic hydrocarbons) [1]. A special role belongs to surfactants, mycotoxins and a biowafer substances [4]. The production of first ones in USA only has achieved in $1997 \approx 5 \times 10^{9}$ tons [5]. In spite of the fact that the control organs of all countries are recommended the using biodegradable surfactants but their mineralization can not be complete and they accumulate gradually in natural water sources [6]. Acute effects of ChS are well known and the cases of their mass use in big concentrations as results of disasters are described in ditail $[7,8]$. Chronic sub-lethal effects of ChS are associated with the worsening reproductive performance, influence on skin, immune, neural and endocrine systems [9-11]. ChS may be absorbed by phytoplankton, filtrated organisms and vegetables [12-14].

Mycotoxins, including more than 300 individual forms, are produced by different fungi strains [4]. T2-mycotoxin, aflatoxins, searelenone, patulin and others cause a great interest since they are widespread and characterized by high level toxicity. T2 mycotoxin has more toxic effect (in 400 times) than mustard gas and lewisite $[4,15]$. It is well-known that mycotoxin $\mathrm{T} 2$ was packed into rockets, bombs, cisterns, some explosive cylinders, hand-grenade and they were applied in Laos and Afghanistan as yellow rain $[15,16]$. This mycotoxin may be prepared by very simple way. Both circumstances (simplicity obtaining and high level of toxicity) form a very serious problems since these toxic elements may be as instrument for bioterrorists. It is necessary to mention that the use of toxins in generally among others groups of biological weapon by terrorists is the most probable since viruses and bacteria pose big danger not for victims only but for executors of terrorist act too. Taken into account the global dispersion of $\mathrm{ChS}$ and extreme danger which they present for living organisms there arises necessary to resist imminent catastrophe. In really, such situation is formed when a large scale of production and consumption of $\mathrm{ChS}$ is exist.

Nowadays research related to assessment of the urban environment state with diverse sources of pollution has gained a special importance. Biomonitoring is an important part of environment control. Supplementing the objective information of chemical and physicochemical control by biomonitoring data can bring us closer to an adequate assessment of the environmental situation in the modern city and can lead us to evaluation of the correct ecological zones. The most effective ways to prevent catastrophe are sharply decreasing of ChS entry in environment and permanent their control [17]. If the first one may be achieved in a great extent by waste water purification the second one may be provided by the full measure by involving new instrumental analytical devices, in particular, which are developed on the basis of chemo- and biosensors technology. It is necessary to mention that facilities for the control of environment should be permanently improved as from side of sensitivity and selectivity, simplicity, rapidity and cheapness of analysis as well as in respect of possibility of its performing in on-line regime and in field conditions. For most complete fulfillment of practice demands the special hopes

*Corresponding author: Guidotti M, Institute of Molecular Sciences and Technology (ISTM), National Research Council (CNR), via G. Venezian 21, I-20144, Milano, Italy, Tel: (+39) 02503 14428; E-mail: m.guidotti@istm.cnr.it

Starodub NF, National University of Life and Environmental Sciences of Ukraine Heroyiv Oborony St, 15, Kyiv-03041, Ukraine, Tel: +380 44527 824; E-mail: nikstarodub@yahoo.com

Received August 03, 2015; Accepted September 16, 2015; Published September 26, 2015

Citation: Starodub NF, Guidotti M, Shavanova KE, Taran MV, Son'ko RV (2015) Ways for the Control of the Total Toxicity of Environmental Objects and their Instrumental Providing. J Biosens Bioelectron 6: 180. doi:10.4172/2155-6210.1000180

Copyright: (c) 2015 Starodub NF, et al. This is an open-access article distributed under the terms of the Creative Commons Attribution License, which permits unrestricted use, distribution, and reproduction in any medium, provided the original author and source are credited. 
are on the application of biosensors the development of which was started at the end of 50 and beginning of 60 years of last century. The work in this direction is activated more and more. Today the perspective prototypes are distinguished in both theoretical and practical aspects [17-20].

The main purpose of this article is presentation of some a most effective ways for the control of the total toxicity of environmental objects.

In the beginning of the development of the approaches intended for $\mathrm{ChS}$ control it was used the principles which were worked out on the traditional microbial biotests: transformation microorganisms and characterization of their vital function. So, it was shown that a lot of enzymes (dehydrogenases, phosphatases, urease, glucose-6phosphatase and others) are very sensitive to some ChS. The number of biotests were proposed as: a) characterization of growth and death of bacterial cultures, b) estimation of respiration level according to oxygen consumption by aerobes and increasing of atmospheric pressure of anaerobes; c) determination of the ability of Eschericha coli to produce labeled $\mathrm{CO}_{2}$ in the presence of ${ }^{14} \mathrm{C}$-glucose. The measurement of bioluminescence of microorganisms, in particular, Pseudomonas fluorescens P-17, Vibrio fischeri F1, Pseudomonas leiognathi Sh1 and Vibrio harveyi Ms1 were used too. For the registration of all above numerated parameters it was proposed and industrial produced different devices as Microtox test, Lumistox, Mutatox test and others [21]. In order to accelerate analysis and to fulfill other practice demands about which was mentioned above it is necessary to combine biological sensitive material together with the specific physical surface which direct transforms physical-chemical signal generated by this material into electrical one. Then it is registered, processed by very simple electronic device and presented as visible, or sound, or other form of information. All it is basis of biosensors. Their classification and general characteristics were done in number of review [18-22]. Below it will be detailed data about biosensors which may be used for the control of the total toxicity of environmental objects.

The most often proposed biosensors are on the basis of microorganisms, their level of metabolic activity of which may be estimated according to changes of $\mathrm{pH}$, oxygen consumption or $\mathrm{CO}_{2}$ releasing, redox potential, formation of lactate and heat. For this purpose it was applied: ion-selective field effect transistors (IsFETs), light-addressable potentiometric sensors, amperometric electrodes, micro calorimeters and others [21-23].

Usually different living organisms (crustaceans), fish, algae, fungi, some vegetables and others) are used to control total toxicity of environment. International Standard exists on the basis of the determination of some indexes of Daphnia immobilization [24]. Unfortunately it is a very routine procedure. Other approaches which obtained the practical applications are based on control of oxygen consumption of microorganisms or determination of their luminescence.

Pollen grains of woody and herbaceous plants can be used as the objects for biomonitoring. To assess the degree of pollution by harmful substances, it is important to choose the species of plants that have great areal of habitat, low level of modification and genetic variability, characterized by relative monomorphism, are not endemic, and their meristematic cells are highly sensitive to the effects of mutagens $[25,26]$. The proportion of normally developed and defective pollen is usually estimated in research, and also metabolic indices of pollen grains may be determined. For example, we showed the change in fertility and pollen sterility in plants of common horse chestnut, depending on the degree of anthropogenic impact in the Kiev city [27].

\section{Approach based on the Daphnia using as sensitive object}

We have proposed the principal new approach based on the determination of the chemiluminescence $(\mathrm{ChL})$ level of Daphnia living medium $[24,28,29]$. The differences of signals before and after introducing Daphnia magna into the solution to be analyzed were registered. In the experiments the specimens of Daphnia magna Straus (Cladocera) were used, which were kept in medium according to the rules of International standards [11]. In preliminary experiments it was shown that Daphnias in age about 1-5 days are suitable for experiments [24]. The excitation of the ChL of the medium was registered in the presence of luminol and hydrogen peroxide the optimal concentrations of which were preliminary established. Stationary, semi-portable and portable devices supplied by optrods, high sensitive photomultiplier, or photo resistors were created for the determination of the intensity of ChL (Figure 1). In dependence on source of toxic substances we have obtained deviations of $\mathrm{ChL}$ values from the initial levels, which were in compliance with the intensity of toxic effect. Standard method with immobilization of Daphnia was curried out to compare results obtained by both ways.

Potassium biochromate was used as the standard chemical solution and the toxicity was checked by the generally accepted method (according to index of Daphnia immobilization). Biosensor was based on the determination of level of ChL Daphnia living medium. Some obtained results are presented in Figure 2. It was stated that the generally accepted method allows to revealing $0.1 \mathrm{mg} / \mathrm{L}$ of potassium biochromate as minimal level (Figure 2, above). At the same time the sensitivity of the proposed biosensor approach was almost two order higher (Figure 2, below) [28]. There is necessary to mention that the overall time of analysis had big difference in both case (about $24 \mathrm{~h}$ and $30 \mathrm{~min}$ for the standard accepted and biosensor methods, respectively).

Sensitivity of Daphnia to some mycotoxin was demonstrated [29]. So, diapason of the measurements of $\mathrm{T} 2$ mycotoxin by the standard accepted method was in frame of concentration of $0.01-0.1 \mathrm{mg} / \mathrm{L}$. At the same time in case of the use of the biosensor method this frame was from 0.001 to $1 \mathrm{mg} / \mathrm{L}$. Moreover the level of sensitivity did not depend on time of Daphnia incubation in solution to be analysed. As far as patulin there was possibility to its quantitative determine by the biosensor method in frame of $0.001-1 \mathrm{mg} / \mathrm{L}$ too (Figure 3).
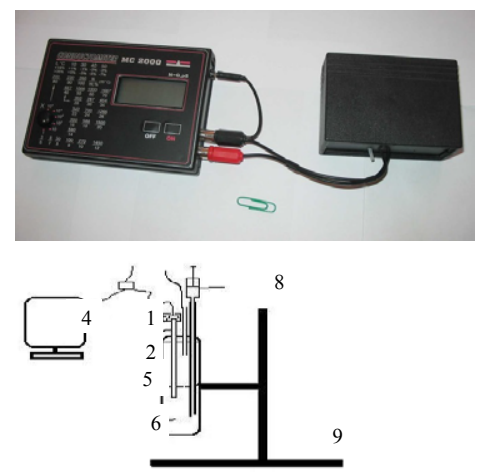

Figure 1: Portable analytical devices (above) for the ChL registration where 1, 2 - electronic block and reactor box, respectively. Optrode based biosensor (bellow), where: 1 - fiber optics with immobilized cells, 2 - photodiod, 3 - system for signal registration, 4 -computer, 5 - glass container, 6 - sample, 7 - syringe for reagent introducing, 8 - pressure compensator, 9 - support. 

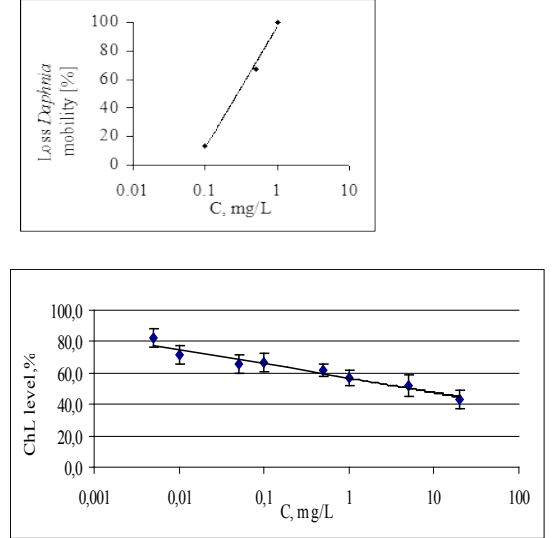

Figure 2: The estimation of biological activity of Daphnia (as sensitive structure) by generally accepted method (above) and the determination of the ChL intensity of living medium of this organism by biosensor (below) after their staying into solution of potassium bichromate with the different concentrations.

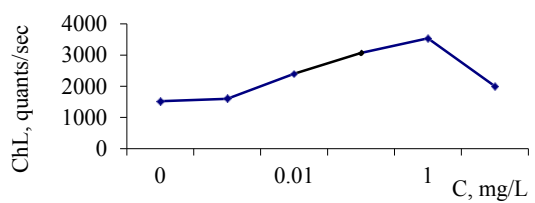

Figure 3: Patulin determination by the biosensor method based on the contro of the ChL level of the Daphnia living medium.

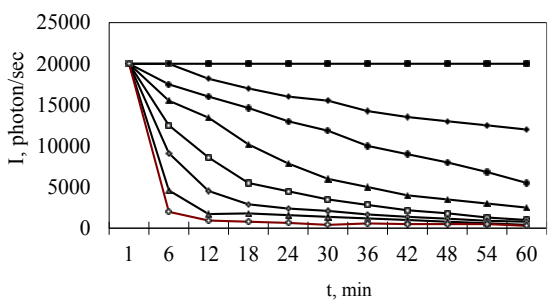

Figure 4: Changes of $\mathrm{Ph}$. Phosphoreum $\mathrm{BL}$ after effect of different patulin concentrations during $60 \mathrm{~min}$. Curves from top-down reflect patulin concentration: $1-8$ - patulin concentration: $0 ; 0.63 ; 1.25 ; 2.5 ; 5 ; 10 ; 20$ and $40 \mathrm{mg} / \mathrm{L}$, respectively.

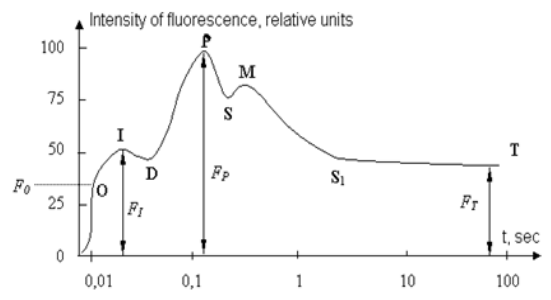

Figure 5: IChF curve, where indicated a different indexes with explanation.

\section{Method with the use of bioluminescent bacteria as sensitive object}

We used Photobacterium phosphoreum K3 (IMB B-7071), V. fischeri F1 (IMB B-7070) and V. fischeri Sh1 purified from Black and Azov Seas $[30,31]$. The level of bioluminescence (BL) was measured by the devices which shown in Figure 1. The samples contented $0.8 \mathrm{~mL}$ of the tested substance in $2.5 \%$ solution of $\mathrm{NaCl}, 0.1 \mathrm{~mL}$ of $0.5 \mathrm{M}$ phosphate $(\mathrm{pH} 7.0)$ or phosphate citrate $(\mathrm{pH} 5.5)$ buffers and $0.2 \mathrm{~mL}$ of the bioluminescent bacterial suspension including $10^{5}$ cells $/ \mathrm{mL}$. In other case bioluminescent bacteria $\left(10^{5}\right.$ cells) were immobilized in sepharose gel (about $0.1 \mathrm{~mL}$ ) and deposited on the end of fiber optics. In both case the BL intensity (I) was registered through 20-120 min.

The level of the T2 mycotoxin toxicity was presented as the concentration, which caused $50 \%$ decrease of the intensity of $\mathrm{BL}\left(\mathrm{EC}_{50}\right)$. The value of $\mathrm{EC}_{50}$ oscillated in range of $7-19 \mathrm{mg} / \mathrm{L}$ in the dependence on time of incubation of bacteria in the T2 mycotoxin solution. It is necessary to accentuate that the sensitivity of $V$. fischeri $\mathrm{F} 1$ to mycotoxin $\mathrm{T} 2$ is much higher in comparison with the sensitivity of Ph. phosphoreum Sq327.

As far increasing of the patulin concentration from 0.63 to $40 \mathrm{mg} / \mathrm{L}$ it caused sufficient decreasing of the BL intensity at the influence on $P h$. phosphoreum Sq3 during 12-60 min (Figure 4). The value of $\mathrm{EC}_{50}$ for patulin was in frame of $0.63-1.25 \mathrm{mg} / \mathrm{L}$ [32]. The dose-effect of patulin at the low concentration (low as $1 \mathrm{mg} / \mathrm{L}$ ) may be confidently registered in case of three repeated measurements for each point. If it follows to this algorithm of analysis the toxic effect of patulin to bioluminescent bacteria may be revealed at the concentration less than $0.15 \mathrm{mg} / \mathrm{L}$.

Moreover with the prolongation of time of influence (up to 90 min) the toxic effect of patulin increased and value of $\mathrm{EC}_{50}$ was in frame of $0.15-0.63 \mathrm{mg} / \mathrm{L}$. At the decreasing of medium $\mathrm{pH}$ to the lower physiological limit (5-5.5) the sensitivity increased up to one order. The value of $\mathrm{EC}_{50}$ has analogy with semi lethal dose established for animal and it correlates with other indexes of toxicity (cytotoxicity, irritation of mucouses, e.a.) [33]. It is necessary to mention that the intestinal barrier in animals is destroyed at the patulin concentration about $1 \mathrm{mg} / \mathrm{L}$ [34]. Taken into consideration of this fact the above indicated data testify that the proposed biosensor analysis with the use of bioluminescent bacteria may be effective at the screening of samples of water, juice, foods and other environmental objects.

At the study of the influence of different types of surface active substances (SAS) on the intensity of bioluminescence of bacteria $(P h$. phosphoreum K3), V. fischeri F1) and V. fischeri Sh1) it was revealed that the main part of the investigated substances are as inhibitors of this process. The analysis of kinetics of inhibition displayed a number of peculiarities. At first, the cationic and anionic SAS had the similar kinetics of inhibition. Second, nonionic SAS, have additional stage on which the inhibition is absent or some activation of bioluminescence is observed. Therefore, for revealing toxicity of this group of SAS it is necessary to incubate these substances with bacteria a long time $[18,19]$.

\section{Method with the use of the chlorophyll fluorescence determi- nation in some plants}

Determination of the chlorophyll fluorescence, a phenomenon known as its induction (IChF) when adapted to the dark green leaves illuminate. It is a promising approach for the diagnosis, as the functioning photosynthetic apparatus and, in general, condition of plants. We studied patterns of IChF parameters during the growing season of plants at affecting on them carbonate chlorosis. Last occupies a special place among the different types of plants such as known that calcareous soils occupy $30 \%$ of the earth's surface. It causes large losses from reduced productivity and death of plants.

For the first time the IChF phenomenon was researched by Kautsky $[35,36]$. Dependence of some indexes of the IChF on time passed after start of lightning of plant's leaves is known as an induction curve or a chlorophyll fluorescence induction curve (Figure 5). The form of this curve is rather sensible to changes in the photosynthetic apparatus of plants during adaptation to different environmental conditions. This 
fact is a basic for extensive usage of Kautsky effect in photosynthesis research. The advantages of the method are the following: high selfdescriptiveness, expressiveness, non-invasiveness and high sensibility.

According to IChF curve it was calculated the next indexes: $(\mathrm{O}$ I) - background level of fluorescence; (I-D) - rapid recovery QA in the complexes of the photosynthetic system 2 which take part in electron transport on the pool of plastoquinones; (D-P) - more slowly reduction of QA in the complexes of the photosynthetic system 2; (P$\mathrm{S})$ - activation of the feredoksin-NADP+-reductase, accumulation of gradient of protons; (S-M) - slowing the outflow of electrons from electron-transport chain to feredoksin-NADP+-reductase caused by decreasing NADP+ pool in case of the delay in $\mathrm{CO}_{2}$ fixation and reduction of gradient of protons due to activity of ATP-synthetase; (M$\mathrm{T})$ - start in active $\mathrm{CO}_{2}$ fixation, $\mathrm{T}$ - stationary level.

The main fields of the application of the method of the fluorescence registration are in the estimation and prediction of the influence of a number of factors on the vital functions of the chlorophyll contented organisms: 1) climatic conditions; 2) fertilizers; 3) substances contaminated environment; 4) viral infection; 5) chemical plant protection and 6) water regimes [37-39]. Moreover, there is possible to select optimal processing methods for the commercial cultivation of crop plants, to provide monitoring and control of productive plants in real time and perform screening control of the environment in certain regions.

Condition photosynthetic apparatus of the plant of yellow lupine, affected by the carbonate chlorosis, was determined with the help of the portable fluorometer "Floratest" developed in the VM Glushkov Institute of Cybernetics of National Academy of Sciences of Ukraine (Figure 6) [39,40].

During the research of the flow of the rapid phase of IChF the next defining parameters were fixed: Fo - level fluorescence of complexes photosystem II (PS II) with "open" reaction center (RC), where Qa are oxidized state; Fm - fluorescence intensity at "closed" RC of FSII when all $\mathrm{Qb}$ recovered and electrons can not be accepted, at last, Fv/Fm - an indicator of potential photosynthetic activity of the leaf.

It is noted that the change of the fluorescent indicators in carbonate and control plants, has a significant impact during the vegetations. In plants affected by the carbonate chlorosis the background level of fluorescence (Fo) at 28 days of the growing season was $544 \pm 6.5$ relative units (rel. units). It exceeds on 40 rel. units the value of this indicator in control. Further, the difference between the variants decreased and was about 12 rel. units. Parameter of Fm value in both groups of plants (experimental and control) on 36 day growing season is increased but it prevailed in diseased plants. Photosynthetic activity of the leafs which was determined by the parameter $\mathrm{Fv} / \mathrm{Fm}$, in plants control group remained invariable during the whole observed period. At the some time, in the plants affected by carbonate chlorosis in the early stages of observation the value of this indicator was lower compared with the control and subsequently the rate of photosynthesis dominated in diseased plants.
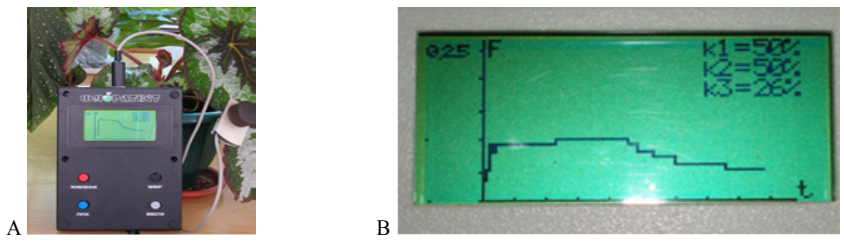

Figure 6: Overall view of the "Floratest" $(\mathrm{A})$ and general form of the result presentation on the monitor of this device $(B)$.
As one of example of the effective application of the new generation above mentioned instrumental tool may serve the express estimation of the horse chestnut state [41].

Today there is a great methodological arsenal for the diagnosis of viral, bacterial and fungal infections of plants. First of all, it is the biological testing of viral diseases on herbaceous indicator plants, methods of electron and immunofluorescence microscopy, various modifications of ELISA, immunodiffusion reaction, serological tests. Today for the express determination of damage of plants by the chestnut moth in vivo it is widely used the method based on the visual examination. Of course, it does not meet current requirements practices for preliminary diagnosis of diseases. As a result of anthropogenic influence, as well as because of pests and diseases a significant amount of chestnut plantations in Kiev is in critical condition. The significant damage to the mentioned above plantations causes the rapid spread of such pest, as chestnut leaf-mining moth.

The effectiveness of the IChF method was studied [40] at the estimation of the functional state of the photosynthetic activity of the horse chestnut and red buckeye in green areas of three ecological zones of Kiev: Botanical Garden of the National University of Life and Environmental Sciences of Ukraine (used as control), Golosiivskyi and Mariinsky parks as well as street plantations near highways. The study were done using the prototype portable device "Floratest".

It was found that the representative plants in three ecological zones have a significant difference of the $\mathrm{IChF}$ indexes that reflects the processes of transformation of energy at the early stages of photosynthesis. In plants of Aesculus pavia, which are resistant to leafmining moths, it was observed the increase in the intensity of on Fo $23,3 \%$, maximum fluorescence $\mathrm{Fp}$ on $19.0 \%$ and stationary level $\mathrm{Ft}$ - on $59.1 \%$. These changes in the nature of fluorescence are caused by the increasing in the number of inactive chlorophyll in susceptible plants, which does not transfer excitation energy from the reaction center (Fo), and accompanied by the growth of "integral inductive losses", i.e. an increase in the amount of energy that does not go on photosynthesis and is displayed in slower phases of induction, what is reflected on the Kautsky curve. Spectral fluorescence studies of the infected horse chestnut leaf showed the growth of intensity ratio of shortwave and longwave fluorescent chlorophyll $-\mathrm{F}_{\mathrm{st}}{ }^{680} / \mathrm{F}_{\mathrm{st}}{ }^{740}$, indicating an increase in the degree of reducing vectors electron transport chain between the reaction centers of photosystems 1 and 2. Also it should be noticed the reduction of fluorescence factor by $21 \%$ ratio of fluorescence induction $\mathrm{Ki}=(\mathrm{Fr}-\mathrm{Ft}) / \mathrm{Fr}$, which characterizes the efficiency of dark photosynthetic processes and above all the ribulose - bisphosphate carboxylase activity - the main enzyme of Calvin cycle.

In samples of plants, susceptible to damage, Fo value decreased by $25.0 \%$ compared to resistant forms, what may happened due to the blocking resynthesis of chlorophyll degradation and destruction of chloroplast structure, reducing their number influenced by complex environmental factors. This, in turn, promotes the decline of maximum fluorescence ( $\mathrm{Fr}$ ) on $29.0 \%$, compared with an increase in its value on $15.0 \%$ in the resistant plants. The most significant change is the intensity of dark photosynthetic process, reflecting the slow change of IChF curve. On the background of general decline in chlorophyll fluorescence emission in resistant plants it was noticed the growth in the level of $\mathrm{Ft}$ by $52.2 \%$. Under these conditions, fluorescence induction coefficient $(\mathrm{Ki})$ is reduced in the comparison with susceptible plants by $73 \%$. This means, the blocking the photosynthetic processes in chloroplasts of the horse chestnut leafs has place. 
Among the parameters of $\mathrm{IChF}$ the plateau coefficient $(\mathrm{Kpl}=(\mathrm{Fpl}-$ Fo):(Fp-Fo) $=\mathrm{dFpl} / \mathrm{Fv}$, where: dFpl=Fpl-Fo - amplitude of the fluorescence plateau; Fv=Fr-Fo - variable fluorescence) most clearly characterizes the resistance of horse chestnut to the normal biotic factors. It was noticed the significant increase in the value of $\mathrm{Kpl}$ in horse chestnut with conventional street stands near the highway, compared with the same option in the red variant of this tree (respectively 0.340 and 0.114$)$. The value of $\mathrm{dFpl} / \mathrm{Fv}(\mathrm{Kpl})$, which characterizes the relative amount of inactive reaction centers in relation to the total number of reaction centers, defined as a test indicator for high adaptability of Aesculus pavia.

The value $\mathrm{dFpl} / \mathrm{Fv}$, which corresponds to the relative amount of non-renewable Qb-PS2 complexes that are not involved in linear electron transport is increased (according to embodiments of the experiment with Aesculus pavia conventional 2.9 and 2.7 times). Note that chlorophyll fluorescence emission increases and in the slow phases the maximum on the induction curve $\mathrm{Fp}$ is $15.5-19.4 \%$. Accordingly, the ratio of fluorescence induction is reduced on $57-58 \%$, indicating a significant inhibition of both photophysical and photochemical processes of photosynthesis in susceptible plants. Least these indicators declined in plants of both species sampled in park areas, indicating on a significantly lower level of human impact on them than those who were on the roads. And, then, plants from parklands has the best overall physiological condition.

It was stated that value of Kpl plateau in the curve of Kautsky can be used as a test for the early selection of the forms of horse chestnut, which are resistant to the influence of the complex environmental factors. The level of $\mathrm{Kpl} \geq 0.4-0.5$ indicates susceptibility to defeat the chestnut moth genotypes of plant species, especially among street plantings near highways.

In others experiments it was analysed the dependence of the IChF indexes of the beans (Phaseolus vulgaris L.) as important agricultural crop that is grown in different regions of Ukraine on the conditions of its grow to predict yields [42].

It was found that the level of adaptation to stress in bean leaves that grew on acidified, salted, excessively drained soils was $0.02 ; 0.07$ and 0.23 rel. units, respectively. While in control experiments, this value had 0.26 . The results indicated that the fluorescent indices are sensitive to the effects of such stressors as acidification, salinity, dehydration. All these conditions lead to a decrease in indices Rfd (690) and Rfd (740). The overall level of fluorescence of chlorophyll in the leaves of beans that grew under the above mentioned conditions was 960, 864 and 928 rel. units, respectively. While in the control experiments this value was reached the level of 1024 and above.

Thus, the used rapid method can significantly speed up the process of selection of resistant to the influence of external factors, including the damaged by pests, plant forms, in the comparation with the visual methods.

Moreover, in general, this approach can be effectively used for the express control of several states of many different species of plants for immediate correction of the situation.

\section{Using fertility of grains like test system for the detection of undifferentiated negative impact of environmental factors}

It is known that fertility is the ability of living organisms to reproduce, ability to give viable offspring, while sterility is complete or partial inability to form viable germ cells or reproduce offsprings [40-
42]. Therefore, the ability to form fertile pollen is an important indicator of plant body general state. Fertile pollen grains of horse chestnut plants have close to spherical shape. The cytoplasm is closely adjacent to the cell wall. Predominantly mature pollen grains with two spermatozoa and one vegetative nucleus were found in the flowering phase. Fixation of anthers was conducted in the Karnua fixator using rectified ethanol and glacial acetic acid in a ratio of 3:1 for 3 hours. Further the material was stored in a solution of $70 \%$ of ethanol. For the determination of the fertility of pollen grains the acetocarmine methodology was used [42]. Samples were studied in the "Laboval" light microscope at X200 magnification and the total number of pollen grains that are divided into fertile and the sterile group were counted.

It was found that fertile pollen grains in the cytoplasm become intense pink, while being painted by acetocarmine, and spermatozoa into dense carmine-red colour (Figure 7).

Unlike the fertile grains, sterile pollen ones are almost resistant to the acetocarmine action or their color is uneven. Their content is usually separated from the cell membrane and is in various stages of degradation. There were no spermatozoa in studied pollen grains.

The objects of the research were woody plants Aesculus hippocastanum L., 30-40 years of age, that are the most common in street and park plantings in Kyiv.

According to the degree of intensity of anthropogenic factors on ecological systems in the investigated area allocated 3 ecological zones of Kyiv [43]: zone No.1 - conditionally clean area with minimized influence of city environmental factors; zone No. 2 - parks under the significant impact of emissions vehicles, but is quite isolated from the negative conditions of the city and the zone No. 3 - main planting along streets with heavy traffic vehicles.

As the control we selected conventionally clean zone No.1 - MM Gryshko Nat. Botanic Garden; No. 2 - Golosiiv forest and No. 3 - street green plantations near to motorways with heavy traffic (Odes'ka square, MTRylskiy Park). All the mentioned zones were choosen according to early fulfilment investigations according to separation zones in cities with the different load levels of the anthropological and mainly due to copious traffic and population density [43].

In a series of experiments it was examined 500 pollen grains from each sampling site, and the pollen fertility ranged from 33.2 to $65.6 \%$ depending on the degree of anthropogenic pressure. In our experiments we showed that the highest level of sterility $(66.8 \%)$ of pollen grains is inherent to the Horse Chestnut trees that grow along the busy traffic roads (Odes'ka square), while the lowest (34.4\%) - in the MM Gryshko National Botanic Garden, where the most favorable conditions for plant growth and development are noticed (Table 1).

Maximum fertility of pollen grains, which is typical for the Horse

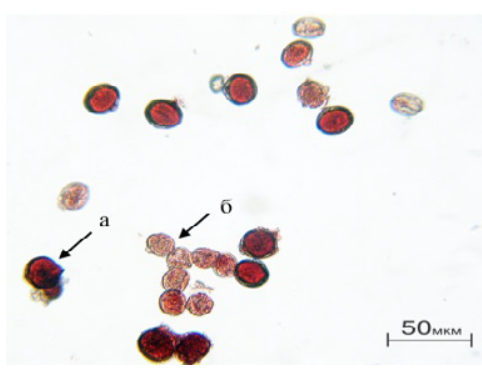

Figure 7: Pollen grains of Horse Chestnut: $a$ - the fertile, $b$ - sterile. 


\begin{tabular}{|l|c|c|c|c|}
\hline \multirow{2}{*}{\multicolumn{1}{|c|}{ Sample location }} & \multicolumn{4}{|c|}{ Pollen grains } \\
\cline { 2 - 5 } & \multicolumn{2}{|c|}{ Fertile } & \multicolumn{2}{c|}{ Sterile } \\
\cline { 2 - 5 } & pcs. & $\%$ & pcs. & $\%$ \\
\hline $\begin{array}{l}\text { MM Gryshko Nat. Botanic } \\
\text { Garden }\end{array}$ & $328 \pm 29$ & 65.6 & $172 \pm 16$ & 34.4 \\
\hline Golosiiv forest & $244 \pm 22^{*}$ & 48.8 & $256 \pm 23^{*}$ & 51.2 \\
\hline Odes'ka square & $166 \pm 14^{*}$ & 33.2 & $334 \pm 32^{*}$ & 66.8 \\
\hline MT Rylskiy Park & $178 \pm 17^{*}$ & 35.6 & $322 \pm 27^{*}$ & 64.4 \\
\hline
\end{tabular}

* Probable on the $5 \%$ significance level. Explanation given in the text.

Table 1: Fertility and sterility of Horse Chestnut pollen grains in different environmental conditions in Kyiv (Ukraine).

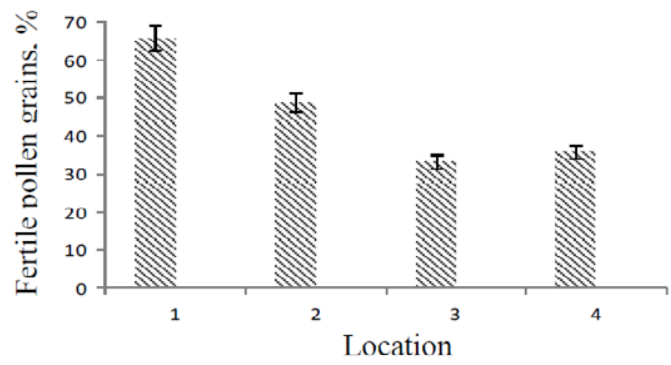

Figure 8: Fertility of Horse Chestnut pollen grown under different places: 1M M Gryshko Nat. Botanic Garden, 2 - Golosiiv forest, 3 - Odes'ka square, 4 - MT Rylskiy Park.

Chestnut trees in the MM Gryshko National Botanic Garden is almost twice the minimum, which was noticed in the Odes'ka square region (Figure 8). High degree of sterility and deformation of pollen grains in some areas in Kyiv may be due to the influence of pollutants, disturbance phytohormonal balance, lack of mineral nutrients, pests and diseases, including Cameraria ohridella Deschka et Dimic and ascomycetes Guignardia aesculi (Peck) Stev. etc.

The obtained results allows suggesting that different levels of sterility of horse chestnut pollen grains in the research areas can be explained by different degrees of anthropogenic factors manifestation about which was mentioned above. Inverse relationship between the number of fertile pollen grains and the degree of anthropogenic pressure in above mentioned zones was found. So, we can to suggest the pollen grains of horse chestnut as a test system for the estimation of the level of anthropogenic pressure since they vastly reflect the cumulative effect of pollutants on ecosystems which were discussed early [44-46]. Although all ecosystems are subjected to anthropogenic pressure, the most severe is the situation in urban ecosystem. In terms of Kyiv-city A. hippocastanum suffer from drought since asphalt coating promotes rapid water drainage and excessive heat, which leads to drying of the soil. It also suffers from smoke and gas contamination of air, delivered by transport. Also, negative impact on Horse Chestnut plants plants can be caused by such factors as soil salinity, heavy metals and harmful chemicals contamination [45]. In adverse conditions of anthropogenic pressure on ecosystems in urban regions occurs a constant pressure on the limits of genotype normal response, reducing viability and reproductive potential of plants [46].

\section{Yeasts as testing objects at the control of total toxicity}

Yeasts are considered as "model organism" since they are simultaneous as unicellular and eucariotic organisms most of the genes and proteins in yeast are human homologues as well as a deeper study of the yeast genome helps scientists better understand the human genome [47]. Another advantage is its fast growth period. In normal yeast environments population doubling yeast takes 90 minutes, and colonies are usually visible in 2-3 days after their transfer to fresh mediumn [48].

One of the perspective object for the experiments with the determination of level of general toxicity of environment medium is Saccharomyces cerevisiaes [49]. It was studied the potential toxicity of novel nanoparticles and nanomaterials at the brewer's yeast Saccharomyces cerevisiae. Three types of nanocomposites based on Saponite and seven samples of metal oxide nanoparticles were examined in the different concentrations. According to the application of 3-(4,5-dimethylthiazol-2-yl)-2,5-diphenyltetrazolium bromide which is as basis for so-called MTT-test it was estimated the optical density of formasane (ABS value) at the wavelelength of $620 \mathrm{~nm}$. In the comparison with the control the most pronounced effect was observed for nanocomposites SapH+ Nb-Sap-Eto $(0.5 \mathrm{mg} / \mathrm{mL})$ with the values of $\mathrm{ABS}$ in 0.7845 and 0.7852 respectively and for Nb-Sap-Cl $(2.0 \mathrm{mg} / \mathrm{mL})$ with $\mathrm{ABS}=0.8137$. At the same time, it was shown that in case of the application of the nanoparticles of $\mathrm{SiO}_{2}, \mathrm{NB}_{2} \mathrm{O}_{5}, \mathrm{~K}-10(0.5 \mathrm{mg} / \mathrm{mL})$ and $\mathrm{ZnO}(2.0 \mathrm{mg} / \mathrm{mL})$ the values of ABS were characteresided as 0.5587 ; $0.5481 ; 0.6422$ and 0.5781 respectively.

The experimental data show that studied nano-composites don't have any inhibitory effect on organisms. Our study therefore indicate that the nanoparticles, aimed on disposal the chemical warfare agents are not harmful for the living organisms.

\section{Conclusion}

According to the presented data it is necessary to underline that during the control of the level of general toxicity of environmental objects the choosing appropriate methodical approaches should be not only sensitive and simple, but express with the possibility to fulfill analysis on line and in field conditions. Moreover, there is needed to take in consideration the reveal of toxic effect in respect of eucariotic organisms. That is why, among all discussed above approaches there is possible to underline high efficiency of metod based on the determination of the level of chemiluminescence of Daphnia living medium. Of course, methods based on the control of such parameters as IChF, fertility of grains, bioluminescence of some bacteria are very informative and they are response of all modern practice demands. There is very important to provide all enumerated above methods by the appropriate modern instrumental devices.

\section{References}

1. Vallack HW, Bakker DJ, Brandt I, Broström-Lundén E, Brouwer A, et al. (1998) Controlling persistent organic pollutants-what next? Environ Toxicol Pharmacol 6: 143-175.

2. Barrie LA, Gregor D, Hargrave B, Lake R, Muir D, et al. (1992) Arctic contaminants: sources, occurrence and pathways. Sci Total Environ 122: 1-74.

3. Mulvad G, Pedersen HS, Hansen JC, Dewailly E, Jul E, et al. (1996) Exposure of Greenlandic Inuit to organochlorines and heavy metals through the marine food-chain: an international study. Sci Total Environ 186: 137-139.

4. Mirocha CJ, Pawlosky RA, Chatterjee K, Watson S, Hayes W (1983) Analysis for Fusarium toxins in various samples implicated in biological warfare in Southeast Asia. J Assoc Off Anal Chem 66: 1485-1499.

5. Morse PM (1999) Soaps and Detergents, C\&EN 35-48.

6. Council Directive (1982) 82/242 EEC of March, On the approximation of the laws of the Member States relating to methods of testing degradability of nonionic surfactants on amending Directive 73/404/EEC.

7. Brouwer A, Morse DC, Lans MC, Schuur AG, Murk AJ, et al. (1998) Interactions of persistent environmental organohalogens with the thyroid hormone system: mechanisms and possible consequences for animal and human health. Toxicol Ind Health 14: 59-84. 
Citation: Starodub NF, Guidotti M, Shavanova KE, Taran MV, Son'ko RV (2015) Ways for the Control of the Total Toxicity of Environmental Objects and their Instrumental Providing. J Biosens Bioelectron 6: 180. doi:10.4172/2155-6210.1000180

8. Eriksson P (1997) Developmental neurotoxicity of environmental agents in the neonate. Neurotoxicology 18: 719-726.

9. Birnbaum LS (1995) Workshop on perinatal exposure to dioxin-like compounds V Immunologic effects. Environ Health Perspect 103 Suppl 2: 157-160.

10. Colborn T (1991) Epidemiology of Great Lakes bald eagles. J Toxicol Environ Health 33: 395-453.

11. Mocarelli P, Brambilla P, Gerthoux PM, Patterson DG Jr, Needham LL (1996) Change in sex ratio with exposure to dioxin. Lancet 348: 409

12. Thomann RV, Connolly JP, Parkerton TF (1992) An equilibrium model of organic chemical accumulation in aquatic food webs with sediment interaction. Environ Toxicol Chem 1: 615-629.

13. Kipopoulou AM, Manoli E, Samara C (1999) Bioconcentration of polycyclic aromatic hydrocarbons in vegetables grown in an industrial area. Environ Pollut 106: 369-380.

14. Eriksson G, Jensen S, Kylin H, Strachan W (1989) The pine needle as a monitor of atmospheric pollution. Nature 34: 42-44.

15. Rosen RT, Rosen JD (1982) Presence of four Fusarium mycotoxins and synthetic material in 'yellow rain'. Evidence for the use of chemical weapons in Laos. Biomed Mass Spectrom 9: 443-450.

16. Morris BA, Clifford MN (1985) Immunoassays for Food Analysis, London/NY, Elsevier Applied Science.

17. Starodub MF, Starodub VM (2000) Immunosensors: sources of origin, achievements and perspectives. Ukr Biokhim Zh (1999) 72: 147-163.

18. Starodub NF, Starodub VN (2001) Biosensors and control of pesticides in water and foods. J Water Chem and Technol 6: 612-638.

19. Starodub VM, Starodub NF (2001) Electrochemical and Optical Biosensors: Origin of Development, Achievements and Perspectives of Practical Application. In: Proceedings of NATO ASI "Novel Processes and Control Technologies in the Food Industry", Bozoglu F, et al. (Eds.) IOS Press 63-94.

20. Korpan YI, Soldatkin AP, Starodub NF, El'skaya AV, et al. (1993) Methylotrophic yeast microbiosensor based on ionsensitive field effect transistors for methano and ethanol determination. Anal Chim Acta 271: 203-208.

21. Van der Meer JR, Belkin S (2010) Where microbiology meets microengineering: design and applications of reporter bacteria. Nat Rev Microbiol 8: 511-522.

22. Bevza OV, Shmireva AN, Starodub NF (2002) Thermobiosensors: peculiarities of construction, functioning and perspective of practical application. Ukr Biochem J 2: 10-20.

23. Bousse L (1996) Whole cell biosensors. Sensors and Actuators B: Chemical 34: $270-275$.

24. ISO (1996) Water quality. Determination of the mobility of Daphnia magna Straus (Cladocera, Crustacea) - Acute toxicity test 6341

25. Ivashkevich SP, Levkovets IA, Nazarenko VI, Starodub NF (2002) [Chemiluminescence of daphnia cultivating medium and optimization of conditions for its determination]. Ukr Biokhim Zh (1999) 74: 93-97.

26. Gojster OS, Starodub NF, Chmel'nitskij G (2003) Determination of 2 mycotoxin by chemiluminescent method with the use of Daphnia. Hydrobiol J 5: 85-91.

27. Pilipenko LN, Egorova AV, Pilipenko IV, Starodub NF (2007) Investigation of toxic effect of patulin with the help of biosensorics systems. Food Sci and Technol 35-38.

28. Katsev AM, GoÄ $\neg$ ster OS, Starodub NF (2003) Effect of mycotoxin T2 on bioluminescence intensity of bacteria. Ukr Biokhim Zh (1999) 75: 99-103.
29. Elnabarawy MT, Robideau RR, Beach SA (1988) Comparison of three rapid toxicity test procedures: Microtox, Polytox and activated sludge respiration inhibition. Toxicity Assess 361-370.

30. Mahfoud R, Maresca M, Garmy N, Fantini J (2002) The mycotoxin patulin alters the barrier function of the intestinal epithelium: mechanism of action of the toxin and protective effects of glutathione. Toxicol Appl Pharmacol 181: 209-218.

31. Guadaño A, de la Peña E, González-Coloma A, Alvarez JF (1999) Development of a new bioluminescent mutagenicity assay based on the Ames test. Mutagenesis 14: 411-415.

32. Davidov Y, Rozen R, Smulski DR, Van Dyk TK, Vollmer AC, et al. (2000) Improved bacterial SOS promoterlux fusions for genotoxicity detection. Mutat Res 466: 97-107.

33. Rosen R, Davidov Y, LaRossa RA, Belkin S (2000) Microbial sensors of ultraviolet radiation based on recA':lux fusions. Appl Biochem Biotechnol 89: 151-160.

34. Köhler S, Belkin S, Schmid RD (2000) Reporter gene bioassays in environmental analysis. Fresenius J Anal Chem 366: 769-779.

35. Daunert S, Barrett G, Feliciano JS, Shetty RS, Shrestha S, et al. (2000) Genetically engineered whole-cell sensing systems: coupling biological recognition with reporter genes. Chem Rev 100: 2705-2738.

36. Kautsky H, Hirsch A (1934) Das Fluoreszenzverhalten gruner Pflanzen Biochem Z: 422-434

37. Lichtenthaler HK (1992) The Kautsky effect: 60 years of chlorophyll fluorescence induction kinetics. Photosynthetica 1-2: 45-55.

38. Romanov V, Starodub M, Galelyuka I, Hrusha V (2010) Biosensors for ExpressDiagnostics of Photosynthesis and Acute Viral Infections. In Book: Intelligent Information and Electronic Technology, IIET 9: 104-118.

39. Starodub NF, Son'ko R, Romanov VO, Galelyuka I (2011) Complex of optical biosensors for control of total state of vegetables and estimation of their loading by viruses. In book: "The SENSOR+TEST 2011". Nurenberg: 133-138.

40. Sonko RV, Marchenko OA, Kolomijetz VM, Starodub MF (2012) Influence of technology of growing corn on the indexes of chlorophyl fluorescence. Scientific Bulletin of Nat Univ of Life and Environm Sci of Ukraine: Ser 178: 127-132.

41. Shavanova KE, Taran MV, Marchenko OA, Starodub NF (2013) "Express control of plants general state by using the new generation of the instrumental tools ", Proc. SPIE 90, Biophotonics-Riga 201.

42. Taran MV, Shavanova KE, Marchenko OA, Godlevska OO, Starodub NF (2015) Express instrumental stability assessment of ordinary beans to abiotic stress factors. Scientific reports of Nat Univ of Life and Environmental Sci of Ukraine 2.

43. Gnativ PS (2014) Functional diagnostic of dendroecology: Scientific monograph. Lviv, Prospect "Kamula" 336.

44. Laptev AA (1998) Ecological optimization biogeocenotic cover in modern urbolandscape K Naukova Dumka.

45. Grygoriuk IP, Mashkovskaya SP, Yavorovsky PP, Kolesnichenko AV (2004) Biology of chestnuts. K Logos.

46. Levon FM (2008) The green plantations in anthropogenically transformed medium. K NNC IAE 364.

47. Pausheva ZP (1980) Manual on cytology plants Moscow: Kolos, Moscow.

48. Goffeau A, Barrell BG, Bussey H, Davis RW, Dujon B, et al. (1996) Life with 6000 genes. Science 274: 563-567.

49. Sherman F (2002) Getting started with yeast. Methods Enzymol 350: 3-41. 